\title{
GAYA BAHASA PERBANDINGAN DALAM BUKU CINTA HITAM CINTA PUTIH KARYA NABIL HAMID AL-MA'AZ
}

\author{
Emil Kholif Mulida Azizah ${ }^{1}$, Artifa Sorraya ${ }^{2}$, Yunita Anas Sriwulandari ${ }^{3}$ \\ IKIP Budi Utomo Malang
}

emilkholif23@gmail.com, arrtiefa.soerraya@gmail.com, cikyun2906@gmail.com

\begin{abstract}
Abstrak: Gaya Bahasa adalah cara seseorang pengarang menyampaikan pendapatnya dengan menggunakan bahasa yang indah dan harmonis serta mampu menuansakan makna dan suasana yang menyentuh daya intelektual dan emosi pembaca. Gaya Bahasa Perbandingan yaitu majas ini berusaha mengungkapkan suatu hal dengan cara membandingkan sutu hal atau keadaan dengan suatu hal atau keadaan lain. Menurut pakar lain membandingkan sesuatu dengan yang lain, berarti mencoba menemukan ciri-ciri yang menunjukan kesamaan antara kedua hal tersebut. Peneliti menentukan dua rumusan masalah pada penelitian ini, antara lain: 1) bagaimana gaya Bahasa perbadingan asosiasi dalam buku cinta hitam cinta putih karya Nabil Hamid Al-Ma'az?, dan 2) bagaimana gaya Bahasa perbandingan personifikasi dalam buku cinta hitam cinta putih karya Nabil Hamid Al-Ma'az?. Metodelogi penelitian yang digunakan dalam penelitian ini adalah rancangan kualitatif, hal ini dikarenakan data hasil penelitian diuraikan dengan tidak mengutamakan angka angka, tetapi mengutamakan kedalaman penghayatan terhadap interaksi-interaksi antar konsep yang sedang dikaji oleh peneliti secara empiris. Teknik analisis data yang digunakan adalah antara lain: 1) reduksi data, 2) penyajian data, 3) verifikasi data, dan 4) penyimpulan data. Dari hasil penelitian ini, ditemukan tiga data gaya Bahasa perbandingan personifikasi, dan lima data gaya Bahasa perbandingan asosiasi.
\end{abstract}

Kata Kunci:Gaya Bahasa, Perbandingan, Buku cinta hitam cinta putih

\section{STYLE OF LANGUAGE COMPARISON IN 'HITAM CINTA PUTIH' BY NABIL HAMID AL-MA'AZ}

Abstract: Language style is the way that an author conveys his or her opinion using a language that is beautiful and harmonious and able to address meaning and atmosphere that can touch the intellectual power and emotion of the reader. The style of comparative language is this majas trying to reveal things by comparing sutu things or circumstances with a thing or other circumstance. According to other specialists comparing something to another, it is trying to find traits that show similarities between the two. Researchers determined two problems in the study, among others: 1) How the Association of Language of the corporation in a white Love Black book by Nabil Hamid Al-Ma'az?, and 2) How to style comparative personification in love books Black Love White by Nabil Hamid Al-Ma'az?. The research methodelogi used in this research is a qualitative design, this is because the data of research results is described by not prioritizing numeric figures, but 
prioritizing the depth of the passion for interactions Which is being examined by empirical researchers. The data analysis techniques used are: 1) data reduction, 2) data presentation, 3) data verification, and 4) data removal. From the results of this study, were found three language style comparison data personification, and five data style comparison association languages.

Keywords: style language, comparison, love book Black Love White

\section{PENDAHULUAN}

Majas dapat diartikan sebagai kekayaan bahasa seseorang yang dapat dimanfaatkan dalam berkomunikasi (lisan maupun tulis) untuk mencapai dampak tertentu, baik dampak semantik maupun dampak estetik (Tjahjono, 2010: 42). Gaya bahasa dalam karya satra mengandung pengertian cara seseorang pengarang menyampaikan gagasannya dengan menggunakan media bahasa yang indah dan harmonis serta mampu mengapikasikan makna dan suasana yang dapat menyentuh emosi pembaca (Aminuddin, 2010: 72). Pada (Keraf, 2009: 113) menyatakan bahwa gaya bahasa adalah cara mengungkapkan pikiran melalui bahasa yang secara khas yang memperlihatkan jiwa dan kepribadian penulis (pemakai bahasa).

Majas merupakan cara yang dipakai pembicara atau penulis untuk mendayagunakan potensi bahasa sedemikian rupa agar tercapai efek semantik estetik pada diri pendengar atau pembaca. Dengan demikian, isi dan pesan yang ingin disampaikan dapat dipahami pendengar atau pembaca (Tjahjono, 2010: 56).Gaya bahasa bagian dari diksi yang mempersoalkan cocok tidaknya pemakaian kata, frase atau kalimat yang mengandung corak tertentu. Adapun jangkauan gaya bahasa tidak hanya unsur kalimat tertentu, seperti dalam retorika klasik (Keraf, 2008: 112). Seperti yang dikatakan Darmawan (2001: 27) dalam apresiasi prosa fiksi bahwa letak keistimewaan bahasa suatu karya sastra semata-mata bukan disebabkan oleh adanya berbagai pigura bahasa, melainkan oleh kemampuan dan keterampilan penulis dalam memilih kata dan menyusunnya menjadi kalimat yang efektif dan efisien. Berkomunikasi lisan maupun tulisan, setiap orang dapat mengekspresikan gagasangagasannya, bahkan dapat mengembangkan suatu kebudayaan. Salah satunya adalah karya seni prosa fiksi.

Gaya Bahasa Perbandingan, sesuai dengan namanya majas ini berusaha mengungkapkan suatu hal dengan cara membandingkan sutu hal atau keadaan dengan suatu hal atau keadaan lain (Tjahjono, 2010: 57). Menurut pakar lain membandingkan sesuatu (Keraf: 2009: 136) dengan yang lain, berarti mencoba menemukan ciri-ciri yang menunjukan kesamaan antara kedua hal tersebut. Perbandingan sebenarnya mengandung dua pengertian, yaitu perbandingan yang termasuk dalam gaya bahasa yang polos atau langsung, dan perbandingan yang termasuk dalam gaya bahasa kiasan. Gaya bahasa perbandingan memiliki banyak subragam (Tjahjono, 2009: 57). Pada penelitian ini hanya menganalisis 2 ragam gaya Bahasa perbandingan. Ragam gaya Bahasa perbandingan tersebut adalah gaya personifikasi dan gaya Bahasa asosiasi/ perumpamaan. Personifikasi atau penginsanan adalah majas yang melukiskan bahwa benda-benda tidak bernyawa atau keadaan bias berperilaku seperti 
layaknya manusia.Gaya perbandingan asosiasi itu dinyatakan dengan kata-kata bagai, seperti, laksana, bak, dan sebagainya.

Pada penelitian ini peneliti menentukan dua rumusan atau fokus masalah, rumusan masalah itu antara lain: 1) bagaimana gaya Bahasa perbadingan asosiasi dalam buku cinta hitam cinta putih karya Nabil Hamid Al-Ma'az?, dan 2) bagaimana gaya Bahasa perbandingan personifikasi dalam buku cinta hitam cinta putih karya Nabil Hamid Al-Ma'az?. Tujuan penelitian ini berkorelasi pada rumusan masalah tersebut. Tujuan penelitian tersebut antara lain: 1) mendeskripsikan gaya Bahasa perbadingan asosiasi dalam buku cinta hitam cinta putih karya Nabil Hamid AlMa'az?, dan 2) mendeskripsikan gaya Bahasa perbandingan personifikasi dalam buku cinta hitam cinta putih karya Nabil Hamid Al-Ma'az.

\section{METODE}

Rancangan penelitian ini menggunakan rancangan kualitatif, hal ini dikarenakan data hasil penelitian diuraikan dengan tidak mengutamakan angkaangka, tetapi mengutamakan kedalaman penghayatan terhadap interaksi-interaksi antar konsep yang sedang dikaji oleh peneliti secara empiris. Hal ini sejalan dengan pendapat Moleong (2010: 6) menjelaskan bahwa penelitian penelitian kualitatif adalah penelitian yang digunakan untuk memahami fenomena tentang apa yang dialami oleh subjek penelitian secara holistik dengan cara deskriptif dalam bentuk kata-kata dan bahasa pada suatu konteks, khususnya yang alamiah dengan memanfaatkan berbagai metode alamiah. Penelitian kualitatif merupakan jenis penelitian yang mencoba menafsirkan suatu masalah yang timbul dari subjek dengan menggunakan media bahasa yang merupakan metode alamiah untuk mendeskripsikan berbagai masalah. Data adalah sumber informasi yang akan diseleksi sebagai bahan analisis. Oleh karena itu, kualitas dan ketepatan pengambilan data tergantung pada ketajaman menyeleksi yang dipandu oleh penguasaan konsep atau teori.

Data dalam penelitian ini berupa kata, kalimat, dan paragraf yang terdapat pada buku cinta hitam cinta putih karya Nabil Hamid Al-Ma'az. Menurut Lofland (dalam Moleong, 2000:112) sumber data utama dalam penelitian kualitatif adalah kata-kata, dan tindakan selebihnya adalah data tambahan seperti dokumen lain-lain. Pada penelitian ini sumber data diperoleh dari buku cinta hitam cinta putih karya Hamid Al-Ma'az dengan identitas buku sebagai berikut:

\begin{tabular}{|l|l|}
\hline Judul Buku & Cinta Hitam Cinta Putih \\
\hline Pengarang & Nabil Hamid Al-Ma'az \\
\hline Tempat Terbit & $\begin{array}{l}\text { Maguwoharjo, Depok, Sleman, } \\
\text { Jogjakarta }\end{array}$ \\
\hline Penerbit & Garasi \\
\hline Tahun Terbit & 2007 \\
\hline Cetakan & Ke-2, Agustus 2007 \\
\hline Halaman & 154 Halaman \\
\hline
\end{tabular}


Instrument penelitian adalah peneliti itu sendiri. Jadi peneliti adalah instrumen kunci dalam penelitian (Sugiyono, 2008:222). Penelitian kualitatif sebagai humen instrument, berfungsi menetapkan fokus penelitian, memilih informan sebagai sumber data, menilai kualitas data, melakukan pengumpulan data, menafsirkan data, dan membuat kesimpulan atas temuanya. Oleh karena itu dalam penelitian kualitatif "the researcher is the key instrument". Penafsiran dengan pemahaman dan penghayatan terhadap sumber data, peneliti memerlukan instrumen bantu berupa format panduanProsedur penelitian ini dibagi menjadi tiga kegiatan, yaitu: (1) tahap persiapan, (2) tahap pelaksanaan, (3) tahap penyelesaian.

Teknik analisis data yang digunakan dalam penelitian ini menggunakan metode hermeneutika. Secara etimologis hermeneutika berasal dari bahasa hermeneuein, bahasa Yunani, yang berarti menafsirkan atau menginterpretasi. Secara mitologis hermeneutika dikaitkan dengan Hermes, nama Dewa Yunani yang menyampaikan pesan ilahi kepada manusia. Pada dasarnya medium pesan adalah bahasa, baik bahasa lisan maupun tulisan. Jadi, penafsiran disampaikan lewat bahasa. Karya sastra perlu ditafsirkan. Oleh sebab itu, satu pihak karya sastra terdiri atas bahasa, di pihak lain, di dalam bahasa sangat banyak makna yang tersembunyi, atau dengan sengaja disembunyikan (Nyoman, 2010: 44). Peneliti menggunakan analisis data kualitatif untuk menganalisis data gaya bahasa dalam buku cinta hitam cinta putih karya Nabil Hamid Al-Ma'az. Langkah-langkah analisis data, antara lain reduksi data, penyajian data, verifikasi data, dan penyimpulan data.

\section{HASIL DAN PEMBAHASAN}

Pada pembahasan ini peneliti membahasa hasil penelitian yang sudah ditentukan dalam rumusan masalah atau fokus masalah. Pada pemaparan sebelumnya peneliti menentukan dua rumusan masalah, rumusan masalah tersebut antara lain: 1) bagaimana gaya Bahasa perbadingan asosiasi dalam buku cinta hitam cinta putih karya Nabil Hamid Al-Ma'az?, dan 2) bagaimana gaya Bahasa perbandingan personifikasi dalam buku cinta hitam cinta putih karya Nabil Hamid Al-Ma'az?. Sebelum menjawab dari rumusan tersebut, peneliti akan memaparkan sinopsis dari isi buku cinta hitam cinta putih karya Nabil Hamid Al-Maaz.

Buku cinta hitam, cinta putih ini mengupas kehidupan dunia remaja kontemporer dan lika-likunya. Dunia remaja dengan berbagai persoalannya, cinta dan seksualitas, dikupas dengan lebih arif dan bijaksana. Buku ini merupakan panduan bagi remaja, bagaimana harus bersikap, mengartikan cinta, menghindari tindakantindakan berbahaya, serta bagaimana mengatur nafsu. Intinya buku ini ingin menunjukkan tentang bagaimana seharusnya perilaku cinta remaja dan menggambarkan secara utuh potret kehidupan serta gejolak remaja pada era sekarang ini. Setelah membaca buku ada beberapa pesan atau amanat yang didapatkan oleh pembaca, oean atau amanat itu antara lain: 1) pembaca dapat mengendalikan diri dan mengendalikan emosi, 2) pembaca mendapatkan tips atau strategi dalam mengelola emosi cinta, 3) pembaca dapat membedakan antara cinta putih atau cinta yang seharusnya atau sewajarnya, dan cinta yang hitam atau cinta yang terlarang, 4) 
pembaca mendapatkan gambaran atau langkah-langkah menuju ke pelaminan atau bahtera rumah tangga, dan bagaimana membangun keluarga berumah tangga.

Hasil analisis gaya Bahasa perbandingan asosiasi terdapat lima data, berikut ini adalah hasil dan pembahasan dari gaya Bahasa perbandingan asosiasi atau perumapamaan.

Data 1:

"sekian banyak pandangan mata sanggup menembus hati sang pemiliknya, bagai tembusan anak panah di antara busur dan talinya"

Kutipan tersebut termasuk dalam gaya Bahasa perbandingan asosiasi karena terdapat kata "bagai", kata tersebut memberikan perbandingan antara banyak pandangan mata sanggup menembus hati pemiliknya dengan tembusan anak panah di antara busur dan talinya. Majas perbandingan asosiasi sangat jelas karena menggunakan kata pembanding "bagai".

Data 2:

"wahai wanita, kau bak pedang yang menyiksaku kalaulah engkau tak pernah ada, aku takkan pernah menjadi sang pencinta yang meluap-luap cintanya.

Aku akan menolak sakitnya mata karena panas dan sering menangis"

Kutipan tersebut termasuk dalam gaya Bahasa perbandingan asosiasi karena terdapat kata "bak", kata tersebut memberikan perbandingan. Majas perbandingan asosiasi sangat jelas karena menggunakan kata pembanding "bak".

Data 3:

"wahai wanita, kau laksana pedang yang menyiksaku sungguh jauh nian kerinduanku dan kecintaanku kepadamu telah menggerakkanku, oh... sakit sang pelipur lara bagi manusia"

Kutipan tersebut termasuk dalam gaya Bahasa perbandingan asosiasi karena terdapat kata "laksana", kata tersebut memberikan perbandingan. Majas perbandingan asosiasi sangat jelas karena menggunakan kata pembanding "laksana".

Data 4:

"kudapati sebuah cinta bagai lampu yang menyala-nyala, hati orang-orang kasmaranlah sebagai bahan bakarnya"

Kutipan tersebut termasuk dalam gaya Bahasa perbandingan asosiasi karena terdapat kata "bagai", kata tersebut memberikan perbandingan. Majas perbandingan asosiasi sangat jelas karena menggunakan kata pembanding "bagai".

Data 5:

"seperti kulit penghuni neraka ketika menjadi matang, dikembalikan lagi untuk menyengsarakan mereka"

Kutipan tersebut termasuk dalam gaya Bahasa perbandingan asosiasi karena terdapat kata "seperti", kata tersebut memberikan perbandingan. Majas perbandingan asosiasi sangat jelas karena menggunakan kata pembanding "seperti".

Hasil analisis gaya Bahasa perbandingan personifikasi terdapat tiga data, berikut ini adalah hasil dan pembahasan dari gaya Bahasa perbandingan personifikasi. Data 1:

"api yang membara terlahir dari percikan api yang kecil"

Kutipan tersebut termasuk gaya Bahasa perbandingan personifikasi karena dari kutipan tersebut memberikan perbandingan dengan cara meletakkan sifat insan 
pada benda mati. Pada kutipan tersebut terdapat kata terlahir, biasanya terlahir itu untuk makhluk hidup, tetapi pada kutipan tersebut yang terlahir adalah api.

Data 2:

"tatkala ia membakar, maka hancurlah hati mereka. Tapi kala hati mereka terbakar, dikembalikan lagi”

Kutipan tersebut termasuk gaya Bahasa perbandingan personifikasi karena dari kutipan tersebut memberikan perbandingan dengan cara meletakkan sifat insan pada benda mati.pada kutipan tersebut terdapat kata membakar, membakar disitu menunjukkan cinta yang membakar hati, sedangkan yang dapat membakar sesuatu adalah manusia buka rasa emosi cinta.

Data 3:

"cinta akan memberinya minum dengan cangkir kematian sebelum saatnya, dan mengantarkannya ke tanah kuburan sebelum datangnya kematian"

Kutipan tersebut termasuk gaya Bahasa perbandingan personifikasi karena dari kutipan tersebut memberikan perbandingan dengan cara meletakkan sifat insan pada benda mati.pada kutipan tersebut terdapat kalimat cinta akan memberinya minum dengan cangkir, cinta itu adalah perasaan emosi yang yang hanya perasaan. Cinta tidak bisa memberinya minum, karena yang dapat memberi minum dengan cangkir hanya insan atau manusia.

\section{KESIMPULAN}

Dari hasil penelitian analisis gaya Bahasa perbandingan dalam buku cinta hitam cinta putih karya Nabil Hamid Al-Ma'az terdapat delapan kutipan gaya Bahasa perbandingan. Gaya perbandingan personifikasi terdapat tiga kutipan, sedangkan gaya Bahasa asosiasi terdapat lima kutipan. Gaya Bahasa perbandingan, ini berusaha mengungkapkan suatu hal dengan cara membandingkan sutu hal atau keadaan dengan suatu hal atau keadaan lain. Gaya perbandingan asosiasi adalah majas yang memberikan perbandingan terhadap suatu hal yang sudah disebutkan menggunakan kata pembanding. Gaya Bahasa perbandingan personifikasi. memberikan perbandingan dengan cara meletakkan sifat insan pada benda mati

\section{DAFTAR PUSTAKA}

Aminuddin, 1987. Sekitar Masalah Sastra. Jakarta: Pustaka Jaya.

Aminuddin. 2013. Pengantar Apresiasi Karya Sastra. Bandung: Sinar Baru

Aglesindo Offset Bandung.

Darmawan. 2001.Apresiasi Prosa Fiksi. Jakarta: Anasco.

Fanannie. 2000. Telaah Sastra. Surakarta: Muhamadiyah University Press.

Keraf, Gorys.2009. Diksi dan Gaya Bahasa. Jakarta: PT Gramedia Pustaka Utama.

Kosasih, Encang. 2003. Kompetensi Ketatabahasaan dan Kesusastraan. Bandung:

Yrama Widya.

Moleong, Laxy J. 2010. Metodologi Penelitian Kualitatif. Bandung: Remaja

Rosdakarya.

Nurgiyantoro, Burhan. 2012. Teori Pengkajian Fiksi. Yogyakarta: Gajah Mada

University Press. 
Ratna, K. Nyoman. 2010.Teori, Metode, Teknik Penelitian Sastra. Yogyakarta: Pustaka Pelajar.

Santos, Wijaya Heru dan Wahyuningtyas. 2010. Pengantar Apresiasi Prosa. Surakarta: Yuma Pressindo.

Sugiyono. 2008. Metode Penelitian Kualitatif dan kuantitatif. Bandung: Alfabeta. Suharsi, Arikunto. 2002. Prosedur Penelitian Suatu Pendekatan Praktek Jakarta: Rinekan Cipta.

Tim Redaksi Kamus Besar Bahasa Indonesia edisi ketiga. 2007. Kamus Besar Bahasa Indonesia. Jakarta: PT (Perseroan) Penerbitan dan percetakan Balai Pustaka. Tjahjono, Tengsoe, 2010. Puisi Mendaki Gunung Ke Arah Kegiatan Apresiasi. Malang: Bayumedia Publishing. 